\title{
BMJ What components of chronic care Open organisation relate to better primary care for coronary heart disease patients? An observational study
}

\author{
Jan van Lieshout, ${ }^{1}$ Eva Frigola Capell, ${ }^{2}$ Sabine Ludt, ${ }^{3}$ Richard Grol, ${ }^{1}$ \\ Michel Wensing ${ }^{1}$
}

To cite: van Lieshout J, Frigola Capell E, Ludt S, et al. What components of chronic care organisation relate to better primary care for coronary heart disease patients? An observational study. 2012;0:e001344. doi:10.1136/bmjopen-2012001344

- Prepublication history and additional material for this paper are available online. To view these files please visit the journal online (http://dx. doi.org/10.1136/bmjopen2012-001344)

Received 19 April 2012 Accepted 20 July 2012

This final article is available for use under the terms of the Creative Commons Attribution Non-Commercial 2.0 Licence; see http://bmjopen.bmj.com

\footnotetext{
${ }^{1}$ Radboud University Nijmegen Medical Centre, Scientific Institute for Quality of Health Care, Nijmegen, The Netherlands

${ }^{2}$ Instituto Universitario Avedis Donabedian (FAD), Universitat Autònoma de Barcelona (Barcelona), Spain ${ }^{3}$ Department of General Practice and Health Services Research, University Hospital of Heidelberg, Heidelberg, Germany
}

Correspondence to Dr Jan van Lieshout; j.vanlieshout@iq.umcn.nl

\section{ABSTRACT}

Objectives: Cardiovascular risk management (CVRM) received by patients shows large variation across countries. In this study we explored the aspects of primary care organisation associated with key components of CVRM in coronary heart disease (CHD) patients.

Design: Observational study.

Setting: 273 primary care practices in Austria, Belgium, England, Finland, France, Germany, The Netherlands, Slovenia, Switzerland and Spain.

Participants: A random sample of $4563 \mathrm{CHD}$ patients identified by coded diagnoses in eight countries, based on prescription lists and while visiting the practice in one country each.

Main outcome measure: We performed an audit in primary care practices in 10 European countries. We used six indicators to measure key components of CVRM: risk factor recording, antiplatelet therapy, influenza vaccination, blood pressure levels (systolic $<140$ and diastolic $<90 \mathrm{~mm} \mathrm{Hg}$ ), and low-density lipoprotein cholesterol $<2.5 \mathrm{mmol} / \mathrm{l}$. Data from structured questionnaires were used to construct an overall measure and six domain measures of practice organisation based on 39 items. Using multilevel regression analyses we explored the effects of practice organisation on CVRM, controlling for patient characteristics.

Results: Better overall organisation of a primary care practice was associated with higher scores on three indicators: risk factor registration $(B=0.0307$, $p<0.0001)$, antiplatelet therapy (OR 1.05, $p=0.0245)$ and influenza vaccination (OR 1.12, $p<0.0001$ ). Overall practice organisation was not found to be related with recorded blood pressure or cholesterol levels. Only the organisational domains 'self-management support' and 'use of clinical information systems' were linked to three CVRM indicators.

Conclusions: A better organisation of a primary care practice was associated with better scores on process indicators of CVRM in CHD patients, but not on intermediate patient outcome measures. Direct support for patients and clinicians seemed most influential.

\section{ARTICLE SUMMARY}

Article focus

- This paper focuses on cardiovascular risk management (CVRM) in patients with coronary heart diseases (CHD) in primary care across Europe.

- A better healthcare organisation is expected to be related to a higher quality of care.

- The aim of our study was to examine which factors of organisation of a primary care practice are associated with quality of CVRM in CHD patients.

\section{Key messages}

- A primary care practice with overall better practice organisation had higher performance scores for risk factor registration, antiplatelet prescription and influenza vaccination in CHD patients.

- A better organisation of 'self-management support' and 'clinical information systems' was associated with higher scores on three performance indicators.

- The difference between a rather poor score and a good score on an organisational domain may improve the outcome up to $30 \%$.

Strengths and limitations of this study

- The international character of our study provided control for contextual confounders, such as specific reimbursement system or national policies.

- Sampling procedures had limitations with respect to representativeness.

- A limitation was that the measures of the organisational domains were post hoc constructed.

\section{INTRODUCTION}

Providing high-quality healthcare for patients with chronic diseases poses major challenges for healthcare systems. In many countries policy makers aim to strengthen the ability of primary care to provide chronic illness care, so that large patient populations can be supported reliably over a long period of time. 
The Chronic Care Model (CCM) proposed that six organisational components are crucial to achieve this: 'healthcare organisation', 'delivery system design', 'decision support', 'clinical information systems, 'selfmanagement support' and 'community resources and policies'. ${ }^{2}$ Box 1 shows a brief description of the six domains. Other organisational models, such as the Patient-Centered Medical Home, ${ }^{3}$ specified similar components. Although these models are based on some research, ${ }^{4-10}$ their positive impact on clinical and preventive performance needs further research as implementing best practices for chronic illness management shows little success. ${ }^{11}$ While it has been claimed that all organisational components are important, it would be informative to get better insight into the relative value of different domains. For instance, a study on diabetes care in 17 centres found that 'delivery system design' was positively correlated to outcomes, whereas 'clinical information systems' and 'self-management support' were not significantly associated. ${ }^{6}$

This paper focuses on cardiovascular risk management (CVRM) in patients with coronary heart diseases (CHD) in primary care across Europe. CHD is a condition with high morbidity and mortality worldwide. ${ }^{12}$ Practice guidelines with recommendations for effective secondary preventive therapy are widely available. ${ }^{13} 14$ Although the effects of antiplatelet therapy and of control of blood pressure and serum cholesterol levels are beyond discussion, research showed that preventive treatment is suboptimal in Europe and the USA. ${ }^{15} 16$ Preventive treatment for patients with established CHD is mostly delivered in primary care, especially in countries with a strong primary care-oriented healthcare system. Substantial variation is observed regarding CVRM received by patients. We expect better healthcare organisation to be related to a higher quality of care.
The aim of our study was to examine which factors of organisation of a primary care practice are associated with quality of CVRM in CHD patients.

\section{METHODS}

This study was part of the EPA Cardio project, an international observational study on cardiovascular risk management in 10 European countries. ${ }^{17}$ The participating countries comprised a convenience sample: Austria, Belgium, England, Finland, France, Germany, The Netherlands, Slovenia, Switzerland and Spain. In stratified samples of primary care practices in each of these countries randomly sampled medical records were reviewed to provide data on cardiovascular risk management and structured questionnaires among participating general practitioners were used to provide data on practice organisation. Practices were stratified according to urbanisation and size sampling based on regional or national lists of practices; in Austria and Switzerland a convenience sample was included. Patients were included based on coded diagnoses in most countries; in Austria prescription lists were used to include patients and in France patients visiting the practice were included when eligible. Data collection took place in 2008-2009.

\section{Indicators for cardiovascular risk management}

Data from medical records were linked to internationally validated indicators on cardiovascular risk management, which were developed in a structured Delphi procedure. ${ }^{18}$ Primary care physician panels from nine countries initially evaluated 650 indicators for cardiovascular risk management. This resulted in a core set of 44 indicators, which were then operationalised in specific measures and tested in a pilot study. ${ }^{19}$ This study is based on

\section{Box 1 Features of the chronic care model}

$\begin{array}{ll}\text { Community resources and policies } & \begin{array}{l}\text { Provider organisations are linked to community-based resources, for example, exercise programmes, } \\ \text { senior centres and self-help groups }\end{array} \\ \text { Health care organization } & \text { Chronic care is seen as a priority with adequate reimbursement } \\ \text { Self-management Support } & \begin{array}{l}\text { Patients themselves become the principal caregivers, taught to manage their illnesses, with lifestyle } \\ \text { issues under the direct control of the patient. } \\ \text { Self-management support involves collaboratively helping patients and their families acquire the skills } \\ \text { and confidence to manage their chronic illness, providing self-management tools and routinely asses- } \\ \text { sing problems and accomplishments } \\ \text { Planned management of chronic conditions is separated from acute care. } \\ \text { Non-physicians support patient self-management, arrange for routine periodic tasks and ensure } \\ \text { appropriate follow-up } \\ \text { Evidence-based clinical practice guidelines provide standards for optimal chronic care integrated into } \\ \text { daily practice. Specialist expertise is available without full specialty referral. Guidelines are reinforced } \\ \text { by educational sessions for practice teams } \\ \text { Registries, a central feature of the Chronic Care Model, are lists of all patients with a particular } \\ \text { chronic condition in a healthcare organisation. Reminder systems help teams comply with practice } \\ \text { guidelines. The system provides feedback showing how each professional is performing on chronic } \\ \text { illness measures. Registries are used to plan both the individual patient care and the population- } \\ \text { based care }\end{array}\end{array}$


performance indicators related to preventive treatments in CHD patients. Data were obtained from patient medical records. The first indicator was an aggregate score which indicated the number of risk factors recorded per patient. Risk factors considered were: smoking behaviour, body mass index, physical activity, blood pressure and cholesterol levels (range 0-5). Five other indicators, all dichotomous, were: a record of antiplatelet therapy unless contraindicated, influenza vaccination offered, systolic blood pressure $<140 \mathrm{~mm} \mathrm{Hg}$, diastolic blood pressure $<90 \mathrm{~mm} \mathrm{Hg}$, and low-density lipoprotein (LDL) cholesterol $<2.5 \mathrm{mmol} / 1$.

\section{Organisation of primary practice}

A large set of questions on practice organisation was included in structured questionnaires, which were partly administered in written form and partly in interviews with the general practitioner in the participating practices who was the research participating contact person. These questions mainly comprised items from the European Practice Assessment (EPA) instrument. This EPA instrument was previously validated in an international project. ${ }^{20}$ We constructed post hoc measures by linking items to one of the six domains of the Chronic Care Model as published before. ${ }^{21}$ All items were formulated positively, with 'yes' indicating the presence of a characteristic. We dichotomised all answers as either 'yes' or 'no', the latter consisting of 'no', 'missing value', or 'not applicable'. The aggregated scores of the following five CCM domains were positively correlated: 'healthcare organisation' (7 items), 'delivery system design' (15 items), 'decision support' (3 items), 'clinical information systems' (6 items) and 'self-management support' (4 items). These correlations were highly significant with Spearman's rho values varying from 0.2 to over 0.6. For that reason, an overall measure of structured chronic care was defined with a scale from 0 to 5 , with equal weight for each CCM domain. Factor analysis showed a Cronbach's $\alpha$ of 0.74. One CCM domain, 'community resources and policies' (4 items), was left out of the overall score due to difference in focus and lower correlation with other domains.

\section{Data analysis}

In order to examine the associations between practice organisation and performance indicators we applied multilevel regression analyses, using indicators for cardiovascular risk management as outcomes. Age and gender were included as explanatory variables (covariates) at the patient level. The second level was the practice level at which the organisational measures were specified. On this level, we entered two factors: the domain 'community resources and policies' was a predictor in all analyses; furthermore, we entered either one of the five other domains or the overall aggregated score. The third level was the country level (as a fixed factor). The analyses were performed for each of the six outcomes separately. The risk factor recording was analysed in a linear regression model, while the dichotomous outcomes, antiplatelet therapy, influenza vaccination, blood pressure and cholesterol levels were handled in binomial logistic regression models. We considered $p$ values of 0.05 or less to indicate statistical significance. Patients with a missing value were ignored for that outcome. For the descriptive data presentation we used SPSS V.16; the regression analyses were conducted using SAS9.

\section{RESULTS}

From the 284 practices in the EPA Cardio study 11 practices were excluded because of low numbers of patients. We included 273 primary care practices with data on 4563 patients (table 1). The number of practices varied from 12 in Finland to 36 in England and Spain. Overall, one-third of the patients were female; in Switzerland and Belgium less than 25\%; in Finland and England about $38 \%$. On average patients were over 69 years of age. Patients in Spain were on average the eldest: over 73 years of age.

Table 2 presents figures on performance indicators. Overall performance varied from $46 \%$ of the maximum score for LDL treatment target and $60 \%$ for systolic treatment target up to $87 \%$ for antiplatelet therapy and diastolic treatment target.

Table 3 presents the results of the regression analyses. Overall better practice organisation was associated with more reliable risk factor registration $(B=0.0307, \mathrm{p}<0.0001)$, antiplatelet prescribing $(\mathrm{OR}=1.0533, \mathrm{p}=0.0245)$ and influenza vaccination $(\mathrm{OR}=1.1246, \mathrm{p}<0.0001)$. The same associations were found for the component 'clinical information systems'. The component 'self-management support' was associated with better risk factor registration $(\mathrm{B}=0.1676, \mathrm{p}<0.0001)$, influenza vaccination (OR 1.55, $\mathrm{p}=0.0004)$ and LDL treatment target (OR 1.15, $\mathrm{p}=0.0252)$. The component 'delivery system design' was associated with better risk factor registration $(\mathrm{B}=0.0352, \mathrm{p}=0.0002)$ and vaccination (OR 1.13, $\mathrm{p}=0.0036)$. The domains

Table 1 Countries, practices and patients included

\begin{tabular}{lllll}
\hline Country & $\begin{array}{l}\text { Number of } \\
\text { practices }\end{array}$ & $\begin{array}{l}\text { Number of } \\
\text { patients }\end{array}$ & $\begin{array}{l}\text { Percentage } \\
\text { of female }\end{array}$ & $\begin{array}{l}\text { Mean } \\
\text { age }\end{array}$ \\
\hline Austria & 23 & 307 & 36.1 & 71.5 \\
Belgium & 23 & 269 & 23.6 & 66.8 \\
England & 36 & 540 & 38 & 67.9 \\
Finland & 12 & 245 & 38.4 & 72.1 \\
France & 25 & 346 & 27.9 & 68.5 \\
Germany & 26 & 463 & 36.9 & 69 \\
The & 35 & 507 & 29.1 & 69.4 \\
Netherlands & & & & \\
Slovenia & 35 & 822 & 35.8 & 68.2 \\
Spain & 36 & 722 & 37 & 73.3 \\
Switzerland & 22 & 342 & 22.4 & 67.8 \\
Total & 273 & 4563 & 33.4 & 69.5 \\
\hline
\end{tabular}


Table 2 Indicators for cardiovascular risk management

\begin{tabular}{|c|c|c|c|c|c|c|}
\hline & $\begin{array}{l}\text { Risk factor } \\
\text { registration } \\
\text { (std. deviation) }\end{array}$ & $\begin{array}{l}\text { Anti-platelet } \\
\text { therapy }\end{array}$ & $\begin{array}{l}\text { Influenza } \\
\text { vaccination }\end{array}$ & $\begin{array}{l}\text { Systolic blood } \\
\text { pressure } \\
<140 \mathrm{~mm} \mathrm{Hg}\end{array}$ & $\begin{array}{l}\text { Diastolic } \\
\text { blood } \\
\text { pressure } \\
<90 \mathrm{~mm} \mathrm{Hg} \\
\end{array}$ & $\begin{array}{l}\text { Low-density } \\
\text { lipoprotein } \\
\text { cholesterol } \\
<2.5 \mathrm{mmol} / \mathrm{l}\end{array}$ \\
\hline Austria & 80.6 (18.6) & 86.4 & 52.8 & 61.4 & 85.9 & 56.1 \\
\hline Belgium & 80.8 (21.2) & 90.7 & 89.2 & 55.9 & 85.2 & 44.8 \\
\hline England & $87.5(16.6)$ & 92 & 86.7 & 69.7 & 95.9 & 65.5 \\
\hline Finland & $70.1(24.4)$ & 93.2 & 72.5 & 50.2 & 84.4 & 65.8 \\
\hline France & $81.4(16.5)$ & 90.4 & 59.1 & 58.9 & 89.5 & 38.2 \\
\hline Germany & 80.4 (19.2) & 67.5 & 71.5 & 58 & 81.3 & 30.4 \\
\hline The Netherlands & $59.8(31.7)$ & 85.2 & 96.4 & 43.6 & 85.7 & 45.1 \\
\hline Slovenia & $77.4(24.8)$ & 93.9 & 31.8 & 56.8 & 79.8 & 38.2 \\
\hline Spain & 58.1 (32.9) & 80.2 & 67.5 & 72.8 & 96.1 & 45.9 \\
\hline Switzerland & 76.8 (24.2) & 95.3 & 55.2 & 65.4 & 87.2 & 46.3 \\
\hline Total & $74(26.8)$ & 87 & 66.1 & 60.1 & 87.1 & 46.3 \\
\hline
\end{tabular}

Percentage of maximum score in risk factor registration (with standard deviation) and percentage of the patients with positive scores for the binary outcomes is shown ( $n=4563$ patients with coronary heart disease).

'healthcare organisation' and 'decision support' were associated with influenza vaccination only. The domain 'community resources and policies' was found to be associated with diastolic blood pressure $<90 \mathrm{mmHg}$.

\section{DISCUSSION}

\section{Main results}

A primary care practice with better practice organisation showed better performance for risk factor registration, antiplatelet prescription and influenza vaccination in CHD patients. These findings support the belief that practice organisation has impact on quality of CVRM in CHD patients across different healthcare systems although the observational design does not allow causal inferences.

In table 4, we illustrate the potential impact of the associations found in our study. It illustrates that the difference between a poorly organised practice and a wellorganised practice was associated with smaller and larger impact on clinical performance. It presents the estimated outcome in a primary care practice with every predictor average except for one, varying this predictor from a 10th percentile score to a 90 th percentile score (to avoid focus on the extremes). With the largest difference as a clear example, an average patient in an otherwise average practice on the lower end (10th percentile) regarding selfmanagement support has a $50 \%$ chance of receiving an influenza vaccination as opposed to a patient in a practice on the better end of the range (90th percentile) having a $79 \%$ chance of receiving an influenza vaccination.

The findings related to 'self-management support' were of particular interest, given the current focus on self-management in the health policies of many countries. In our study the domain related to having information leaflets available in the practice concerning cardiovascular diseases (eg, CHD, stroke, hypertension, stop smoking, etc); presence of a directory of prevention activities/organisations locally available (eg, gyms, walking group and weight-watchers); offering written information on life style regularly; and offering advice about websites for education on health risks or healthy life style regularly. It is encouraging that such practical items are indeed associated with better clinical processes, although the causality remains unknown.

The organisational domain 'clinical information system' referred to access to internet and email in the practice, virus protection, use of a pass word, use of a computer-supported patient file system and computergenerated medication prescriptions. As data on clinical performance depended on medical records, we actually measured to some extent performance and also quality of recording. Optimal use of computerised medical record systems leads to better scores for practice organization and clinical performance. But as CVRM mainly is a collaborative task, healthcare professionals need to be able to rely on the data recorded.

The relevance of a well organised practice mainly concerned preventive procedures (risk factor registration, drug prescription and vaccination) rather than intermediate outcomes of healthcare (blood pressure and cholesterol levels). However, it should be noted that better prescribing of antiplatelet therapy has a well-assessed effect on cardiovascular events and mortality. ${ }^{22}$ Likewise, the benefits of influenza vaccination in preventing complications are well-documented and guidelines recommend vaccination to patients with cardiovascular diseases. ${ }^{13} 1423$ This suggests that better organisation of primary care was indeed associated with improved survival and fewer cardiovascular events in patients with CHD.

Previous research found associations between practice organisation and clinical performance, ${ }^{4-10} 2425$ and a systematic review of trials of organisational interventions 
Table 3 Effects of practice organisation characteristics on indicators of cardiovascular risk management

Linear regression Logistic regression

Risk factor Antiplatelet Influenza

registration therapy vaccination
therapy vaccination

B

p Value

OR p Value

(a) Primary analyses

Age

Gender

$1=$ female

OR p Value

SBP $<140 \mathrm{~mm} \mathrm{Hg}$

DBDP $<90 \mathrm{~mm} \mathrm{Hg} \quad$ LDL $<2.5 \mathrm{mmol} / \mathrm{l}$

OR $\quad p$ Value OR p Value

2=male

Chronic care model-composite (score from 0 to 5 )

Community resources and policies $(n=4)$

(b) Secondary analyses

Healthcare organisation $(n=7)$

Clinical information systems $(n=6)$

$\begin{array}{llll}0.0042 & 0.0207 & 1.0040 \quad \mathrm{NS}\end{array}$

$1.0688<0.0001$

Self-management support $(n=4)$

Decision support $(n=3)$

$1.7695<0.0001$

1.0619 NS

0.9858

0.0036

$0.9886 \quad 0.0035$

0.0307

0.0307

1.0619 NS $-0.9601 \mathrm{NS}$

0.9954 NS

$0.7192 \quad 0.0001$

$\begin{array}{lllllll}0.0001 & 1.0533 & 0.0245 & 1.1246 & <0.0001 & 1.0028 & \text { NS }\end{array}$

1.0091 NS $\quad 1.0037$ NS

0.0280

0.8513 NS $\quad 1.0078$ NS

$1.1556-0.0283-1.1035$

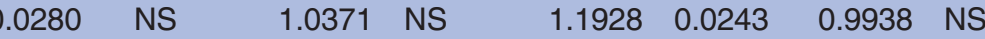

$\begin{array}{llllllll}0.0498 & 0.0236 & 1.3192 & 0.0016 & 1.4768 & 0.0002 & 1.0575 & \mathrm{NS}\end{array}$

$\begin{array}{llllllll}0.1676 & <.0001 & 1.0539 & N S & 1.5477 & 0.0004 & 0.9685 & N S\end{array}$

$\begin{array}{llllllll}0.0685 & N S & 1.1954 & \text { NS } & 1.4338 & 0.0411 & 1.0767 & \text { NS }\end{array}$

Delivery system design $(n=15)$

$0.0352 \quad 0.0002 \quad 1.0597$ NS

$\begin{array}{lll}1.1342 & 0.0036 & 1.0022\end{array}$

$0.9807 \quad N S \quad 0.9802$ NS

$1.0558 \quad N S \quad 0.9627$ NS

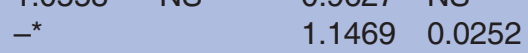

1.0664 NS $\quad 1.1165$ NS

0.9763 NS 1.0033 NS

Results of regression analyses ( $\mathrm{B}$ values and $\mathrm{OR}$ ) with $\mathrm{p}<0.05$ as significance level, a three-level model.

Three level model: outcomes on patient leve

Primary analysis: practice level with two variables: (1) community resources and policies and (2) the Chronic Care Model composite score of the other five domains, comprising healthcare

organisation, clinical information systems, self-management support, decision support and delivery system design.

Secondary analysis: practice level with two variables: (1) community resources and policies and (2) one of the other five domains: healthcare organisation, clinical information systems,

self-management support, decision support or delivery system design. Only the estimates of these last domains are displayed in this analysis.

*Analysis found no estimate.

DBP, diastolic blood pressure; B, effect estimate in regression analysis; LDL, low-density lipoprotein cholesterol level; NS, not significant, significance level at p<0.05; SBP, systolic blood

pressure. 
Table 4 Estimated cardiovascular performance for practices with low or high scores on measures of practice organisation

\begin{tabular}{|c|c|c|c|}
\hline & $\begin{array}{l}\text { Performance } \\
\text { indicators }\end{array}$ & $\begin{array}{l}\text { Practice } \\
\text { with low } \\
\text { scores }\end{array}$ & $\begin{array}{l}\text { Practice } \\
\text { with high } \\
\text { scores }\end{array}$ \\
\hline \multirow[t]{3}{*}{$\begin{array}{l}\text { Chronic Care } \\
\text { Model -composite }\end{array}$} & $\begin{array}{l}\text { Risk factor } \\
\text { registration }\end{array}$ & 0.74 & 0.76 \\
\hline & $\begin{array}{l}\text { Antiplatelet } \\
\text { therapy }\end{array}$ & 0.86 & 0.88 \\
\hline & $\begin{array}{l}\text { Influenza } \\
\text { vaccination }\end{array}$ & 0.63 & 0.69 \\
\hline \multirow{3}{*}{$\begin{array}{l}\text { Clinical } \\
\text { information } \\
\text { systems }\end{array}$} & $\begin{array}{l}\text { Risk factor } \\
\text { registration }\end{array}$ & 0.72 & 0.75 \\
\hline & $\begin{array}{l}\text { Antiplatelet } \\
\text { therapy }\end{array}$ & 0.78 & 0.89 \\
\hline & $\begin{array}{l}\text { Influenza } \\
\text { vaccination }\end{array}$ & 0.45 & 0.72 \\
\hline \multirow[t]{3}{*}{$\begin{array}{l}\text { Self-management } \\
\text { support }\end{array}$} & $\begin{array}{l}\text { Risk factor } \\
\text { registration }\end{array}$ & 0.69 & 0.79 \\
\hline & $\begin{array}{l}\text { Influenza } \\
\text { vaccination }\end{array}$ & 0.50 & 0.79 \\
\hline & $\begin{array}{l}\text { Low-density } \\
\text { lipoprotein } \\
<2.5 \mathrm{mmol} / \mathrm{l}\end{array}$ & 0.44 & 0.48 \\
\hline
\end{tabular}

in CHD patients in primary care found limited evidence for effects on outcomes such as blood pressure and serum cholesterol levels. ${ }^{26}$

In our explorative analysis of the relevance of various organisational domains, we found differential effects on performance. The components 'self-management support' and 'clinical information system' were found to be most consistently related to cardiovascular risk management. We cannot rule out the possibility that our measures of these domains may have been more accurate than those of other domains or that the participating primary care practices had specific characteristics explaining the findings. On the contrary, both clinical information system and self-management are directly linked to decisions and behaviours of clinicians and patients, which have known impact on cardiovascular risk. Clinical information systems may be crucial because it is a well-known contribution to the other domains. Self-management support is the one domain targeting the patient, offering another aspect than the care and practice-related domains.

The question is how the impact of organisation of healthcare on (intermediate) patient outcomes can be optimised. Our study may have missed the power to detect small effects. Further down the line (system, process and patient outcomes), more factors become relevant and influential and to prove the effect of care domains subsequently becomes more difficult.

\section{Strengths and weaknesses}

The EPA Cardio study was based on random sampling of patients using well-developed measures of cardiovascular risk management and practice organisation, although the measures of the CCM were post hoc constructed. The international character of our study contributed to its generalisability and provided control for contextual confounders, such as specific reimbursement system or national policies. The sampling of countries and practices had limitations with respect to representativeness, but provided arguably more generalisable evidence than many trials of organisational changes in healthcare. In the patient samples women seemed underrepresented. In various national databases male CHD prevalence is 1.5-2 times the female prevalence. ${ }^{27-29}$ Particularly in Belgium and Switzerland low numbers of females were included which cannot be accounted for. We suggest that the impact of this on our result was limited, because sex and age were controlled for in the analyses.

\section{CONCLUSION}

Our observational study provided data from a real-life situation in contrast with many trials of organisational changes in primary care. We found that a better organised practice, measured in terms of implementation of the Chronic Care Model, had better clinical processes in the targeted cardiovascular domain. Most notably, we found that 'clinical information systems' and 'self-management support' were relevant. The impact on cardiovascular outcomes was less obvious, which may be due to a range of factors. Nevertheless, this study reinforces the importance of strengthening the organisation of primary care practices for improving their clinical performance.

Acknowledgements The following individuals were part of the EPA Cardio group: Stephen Campbell ((UK), Ester Cornelis (Belgium), Glyn Elwyn (UK), Reinhold Glehr (Austria), Margalit Goldfracht (Israel), Hector Falcoff (France), Beat Künzi (Switzerland), Lilian Michlig (Switzerland), Esko Kumpusalo (Finland), Janko Kersnik (Slovenia), Kati Kettunen (Finland), Solene Martin (France), Davorina Petek (Slovenia), Ingrid Pichler (Austria), Martin Roland (UK), Marianne Samuelson (France), Veerle van der Stighelen (Belgium) and Trudy van der Weijden (The Netherlands). Statistical analyses were performed by Jan Mulder and Jan Koetsenruijter.

Contributors JVL had full access to all the data in the study and takes responsibility for the integrity of the data and the accuracy of the data analysis. JvL led decisions about content and submission. All authors contributed to data analysis and interpretation, and the writing and editing of the report. All authors approved the final version of the report.

Funding The study was supported by a grant from the Bertelsmann Foundation, Gütersloh, Germany. The Bertelsmann Foundation had no involvement in study design; in the collection, analysis and interpretation of data; in the writing of the report; and in the decision to submit the paper for publication.

Competing interests All authors have completed the Unified Competing Interest form at http://www.icmje.org/coi_disclosure.pdf (available on request from the corresponding author) and declare: no support from any organisation for the submitted work; no financial relationships with any 
organisations that might have an interest in the submitted work in the previous 3 years, no other relationships or activities that could appear to have influenced the submitted work

Ethics approval Ethical approval was waived in some countries and obtained in other countries.

The ethical committees with references for the approvals granted where appropriate: Austria: Med Uni Graz, Auenbruggerplatz 2, A-8036 Graz, Prof Peter Rehak; Belgium: Commissie Medische Ethiek UZ Leuven, Campus Gasthuisberg, Herestraat 49, B-3000 Leuven; Finland: Ethics committee of the Kuopio University Hospital, Kuopio, Finland; France: Ethic Commitee (Comié de Protection des Personnes Île-de-France V, Hôpital Saint-Antoine 184, rue du Faubourg Saint-Antoine 75012 Paris; Germany: Ethics committee University Hospital: 'Medizinische Fakultät Heidelberg', Alte Glockengießerei 11/1, D-69115 Heidelberg (S-413/2007); The Netherlands: Ethics committee CMO Region Arnhem-Nijmegen; Slovenia: Slovenian national committee on medical ethics (No 87/11/07); Spain: Scientific committee of IDIAP Jordi Gol (Catalan Primary Care Research Institute Jordi Gol), Barcelona, Catalonia, Spain; Switzerland: KEK—Kantonale Ethikkommission, Bern; The UK: North West Research Ethics Committee: 07/H1010/83.

Provenance and peer review Not commissioned; externally peer reviewed. Data sharing statement No additional data available.

\section{REFERENCES}

1. Improving chronic illness care. http://www.improvingchroniccare.org/ (accessed 24 Feb 2012).

2. Bodenheimer T, Wagner EH, Grumbach K. Improving primary care for patients with chronic Illness. JAMA 2002;288:1775-9.

3. ACEP Board of Directors. The patient-centered medical home model. Ann Emerg Med 2009;53:289-91.

4. Tsai AC, Morton SC, Mangione CM, et al. A meta-analysis of interventions to improve care for chronic illnesses. Am J Manag Care 2005;11:478-88.

5. Friedberg MW, Coltin KL, Safran DG, et al. Associations between structural capabilities of primary care practices and performance on selected quality measures. Ann Intern Med 2009;151:456-63.

6. Sperl-Hillen JM, Solberg LI, Hroscikoski MC, et al. Do all components of the chronic care model contribute equally to quality improvement? Jt Comm J Qual Saf 2004;30:303-9.

7. Koelling TM, Johnson ML, Cody RJ, et al. Discharge education improves clinical outcomes in patients with chronic heart failure. Circulation 2005;111:179-85.

8. Bosworth HB, Olsen MK, Grubber JM, et al. Two self-management interventions to improve hypertension control: a randomized trial. Ann Intern Med 2009;151:687-95.

9. Demiris G, Afrin LB, Speedie S, et al. Patient-centered applications: use of information technology to promote disease management and wellness. A white paper by the AMIA knowledge in motion working group. J Am Med Inform Assoc 2008;15:8-13.

10. Chaudhry B, Wang J, Wu S, et al. Systematic review: impact of health information technology on quality, efficiency, and costs of medical care. Ann Intern Med 2006;144:742-52.

11. Bernstein J. The elusive benefits of chronic care management. Arch Intern Med 2011;171: 466-7.

12. World Health Organization. Cardiovascular diseases (CVDs). WHO, 2011. http://www.who.int/mediacentre/factsheets/fs317/en/index. html. (accessed 29 Jul 2011).

13. Graham I, Atar D, Borch-Johnsen K, et al. European Society of Cardiology (ESC), European Association for Cardiovascular Prevention and Rehabilitation (EACPR), Council on Cardiovascular Nursing, European Association for Study of Diabetes (EASD), International Diabetes Federation Europe (IDF-Europe), European Stroke Initiative (EUSI), Society of Behavioural Medicine (ISBM), European Society of Hypertension (ESH), WONCA Europe (European Society of General Practice/Family Medicine), European Heart Network (EHN), European Atherosclerosis Society (EAS). European guidelines on cardiovascular disease prevention in clinical practice: full text. Fourth Joint Task Force of the European Society of Cardiology and other societies on cardiovascular disease prevention in clinical practice (constituted by representatives of nine societies and by invited experts). Eur J Cardiovasc Prev Rehabil 2007;14 (Suppl 2):S1-113.

14. Fraker TD Jr, Fihn SD, Gibbons RJ, et al. American College of Cardiology, American Heart Association, American College of Cardiology/American Heart Association Task Force on Practice Guidelines Writing Group. Chronic angina focused update of the ACC/AHA 2002 Guidelines for the management of patients with chronic stable angina: a report of the American College of Cardiology/American Heart Association Task Force on Practice Guidelines Writing Group to develop the focused update of the 2002 Guidelines for the management of patients with chronic stable angina. Circulation 2007;116:2762-72.

15. Kotseva K, Wood D, De Backer G, et al. EUROASPIRE Study Group. EUROASPIRE III: a survey on the lifestyle, risk factors and use of cardioprotective drug therapies in coronary patients from 22 European countries. Eur J Cardiovasc Prev Rehabil 2009;16:121-37.

16. Chan PS, Oetgen WJ, Buchanan D, et al. Cardiac performance measure compliance in outpatients: the American College of Cardiology and National Cardiovascular Data Registry's PINNACLE (Practice Innovation And Clinical Excellence) program. J Am Coll Cardiol 2010;56:8-14

17. Wensing M, Ludt S, Campbell S, et al. EPA Cardio Project Group. European Practice Assessment of Cardiovascular risk management (EPA Cardio): protocol of an international observational study in primary care. Implement Sci 2009;4:3.

18. Campbell SM, Ludt S, Van Lieshout J, et al. Quality indicators for the prevention and management of cardiovascular disease in primary care in nine European countries. Eur J Cardiovasc Prev Rehabil 2008;15:509-15.

19. Ludt S, Campbell S, Van Lieshout J, et al. Development and pilot of an internationally standardized measure of cardiovascular risk management in European primary care. BMC Health Services Research 2011;11:70.

20. Engels Y, Dautzenberg M, Campbell S, et al. Testing a European set of indicators for the evaluation of the management of primary care practices. Fam Pract 2006;23:137-47.

21. Van Lieshout J, Goldfracht M, Campbell S, et al. Characteristics of primary care in Europe which contribute to chronic disease management: an observational study. Br J Gen Pract 2011;61:25-31.

22. Antithrombotic Trialists' Collaboration. Collaborative meta-analysis of randomised trials of antiplatelet therapy for prevention of death, myocardial infarction, and stroke in high risk patients. $B M J$ 2002;324:71-86.

23. Keller T, Weeda VB, van Dongen CJ, et al. Influenza vaccines for preventing coronary heart disease. Cochrane Database Syst Rev 2008;(3). Art. No.: CD005050. doi:10.1002/14651858.CD005050. pub2.

24. Vargas RB, Mangione CM, Asch S, et al. Can a chronic care model collaborative reduce heart disease risk in patients with diabetes? J Gen Intern Med 2007;22:215-22.

25. Asch SM, Baker DW, Keesey JW, et al. Does the collaborative model improve care for chronic heart failure? Med Care 2005;43:667-75.

26. Buckley BS, Byrne MC, Smith SM. Service organisation for the secondary prevention of ischaemic heart disease in primary care. Cochrane Database Syst Rev 2010;(3). Art. No.: CD006772. doi:10.1002/14651858.CD006772.pub2

27. Scarborough $\mathrm{P}$, Bhatnagar $\mathrm{P}$, Whickramasinge $\mathrm{K}$, et al. Coronary heart disease statistics 2010 edition. http://www.bhf.org.uk/ publications/view-publication.aspx?ps=1001546. (accessed 24 Feb 2012).

28. Gommer AM, Poos MJJC. Prevalentie, incidentie en sterfte naar leeftijd en geslacht. In: Volksgezondheid Toekomst Verkenning, Nationaal Kompas Volksgezondheid. Bilthoven: RIVM, Nationaa Kompas VolksgezondheidlGezondheid en ziektelZiekten en aandoeningen\Hartvaatstelsel\Coronaire hartziekten, 7 December 2010. http://www.nationaalkompas.nl/gezondheid-en-ziekte/ziektenen-aandoeningen/hartvaatstelsel/coronaire-hartziekten/cijferscoronaire-hartziekten-prevalentie-incidentie-en-sterfte-uit-de-vtv2010/ (accessed 24 Feb 2012).

29. Robert Koch-Institut, Berlin 2011. Daten und Fakten: Ergebnisse der Studie'Gesundheit in Deutschland aktuell'. 2009, http://www. gbe-bund.de/ (accessed 24 Feb 2012) 